\title{
ПЛАНИРОВАНИЕ И УПРАВЛЕНИЕ: ОПЫТ, ТЕНДЕНЦИИ, ПЕРСПЕКТИВЫ
}

\author{
(c) 2021 Фоменко Наталья Михайловна \\ доктор экономических наук, профессор кафедры теории менеджмента и бизнес-технологий \\ Российский экономический университет им. Г. В. Плеханова, Россия, Москва \\ E-mail: fnata77@mail.ru
}

(c) 2021 Журавлев Павел Викторович

доктор экономических наук, профессор кафедры теории менеджмента и бизнес-технологий Российский экономический университет им. Г. В. Плеханова, Россия, Москва

E-mail:pzhurav@mail.ru

\section{(c) 2021 Бусалова Аглая Дмитриевна}

ассистент кафедры теории менеджмента и бизнес-технологий

Российский экономический университет им. Г. В. Плеханова, Россия, Москва

E-mail: Busalova.AD@rea.ru

В данной статье проведен анализ исследований в области планирования и управления. Рассмотрена эволюция понятия «управление» на основе анализа трактовок понятия отечественными исследователями. Также авторами представлена методика проведения исследования, практический апробированная на статьях отечественных ученых, размещенных в базе научной электронной библиотеки Elibrari.ru. В результате проведенного анализа выявлено шесть основных направлений научных исследований в сфере организации, планирования и управления, определен период наибольшей публикационной активности отечественных исследований и цитируемости статей, а также определены перспективы развития управленческой науки.

Ключевые слова: управление, планирование, организация, область исследования, современный менеджент

Первая часть XXI века характеризуется глобальными трансформациями в вопросах планирования и управления, а также в традиционном понимании организации экономических отношений. Почти все секторы экономики в настоящее время сталкиваются с фундаментальными технологическими изменениями, обусловленными четвертой промышленной революцией, которая основана на слиянии технологий, объединяющих цифровую, физическую и биологическую среду [1]. Современный менеджмент должен сочетать хорошо известные, проверенные временем способы управления, включая планирование и организацию деятельности предприятия, а также новые подходы, в которых существенную важность приобретают гибкость, умение приспосабливаться к сложным и нестабильным условиям внешней среды, нацеленность на удовлетворение интересов всех заинтересованных сторон и постоянное совер- шенствование деятельности [2]. Таким образом, современные трансформационные процессы требуют разработки и реализации новых моделей управления, а также повышения эффективности планирования и организации деятельности, которые позволили бы повысить уровень конкурентоспособности и способствовать повышению эффективности деятельности организаций. В таких условиях вопросы сочетания традиционных и инновационных подходов менеджмента к планированию и управлению организацией, а также выявления перспектив и направлений ее развития имеют существенную актуальность, поскольку точное восприятие вопросов организации деятельности в современных условиях позволит прийти к пониманию основ и специфики функционирования и развития современных организаций.

Одновременно с трансформационными процессами в понимании вопросов управления

\footnotetext{
* Статья подготовлена в рамках внутреннего гранта РЭУ им. Г. В.Плеханова на выполнение НИР «Компаративный эволюционный анализ трансформации современных концепций менеджмента и определение целевых установок развития российских моделей управления». Утверждена приказом от 7 июня 2021 г. № 652.
} 
организацией идет процесс научного осмысления, ученые определяют новые области исследования и перспектив применения функций менеджмента. Вопросами развития, становления и функционирования систем управления уделено большое внимание в трудах отечественных и зарубежных авторов. Особое внимание этим вопросам уделено в трудах: И.Ансоффа [3], В. Г.Антонова [4], М. Вебера [5], И. В.Денисова [6], М.Н. Кулапова [7], Ю.С.Новиковой [8], Никулина Л.Ф.[9], Ю.Г. Одегова [10], Ф.Тейлора [11], А. Файоля [12] и др.

Одним из главных факторов успеха любой организации является управленческая деятельность, которая подлежит постоянному совершенствованию исходя из условий внешней и внутренней среды. Для обеспечения стабильного функционирования организации и достижения поставленных целей, решения задач, необходимо постоянное управление процессами организации. В общем виде процесс управления можно представить как взаимодействие между субъектом и объектом управления. При этом субъект управления формирует цели функционирования объекта управления и определяет инструменты, с помощью которых существующий или создаваемый объект управления сможет достичь этих целей [13]. Рассматривая трактовки понятия «управление», можно выделить следующие (таблица 1).

Обобщая полученную информацию, можно говорить о том, что большинство определений сводятся к управлению организацией путем воздействия субъектов управления на объекты управления для достижения определенной цели управления при одновременном усложнении управленческих процессов в современных условиях.

Представленное в рамках данной статьи исследование представляет собой частичные результаты работ, проведенных группой ученых при выполнении научно-исследовательской работы на тему «Компаративный эволюционный анализ трансформации современных кон-

\section{Таблица 1. Основные трактовки понятия управления}

\begin{tabular}{|c|c|}
\hline Автор & Трактовка \\
\hline Абчук, В.А [14] & $\begin{array}{l}\text { Процесс переработки информации с целью подготовки, принятия и реализа- } \\
\text { ции решений, обеспечивающих повышение эффективности работы организа- } \\
\text { ции, улучшение качества он продукции }\end{array}$ \\
\hline Виноградова, С.Н. [15] & $\begin{array}{l}\text { Вид индивидуального или группового планомерного воздействия субъек- } \\
\text { тов управления на объекты управления для достижения определенной цели } \\
\text { управления }\end{array}$ \\
\hline Иванова Е.А. [16] & $\begin{array}{l}\text { Вид деятельности, с помощью которой он субъект управления оказывает воз- } \\
\text { действие она управляемый объект }\end{array}$ \\
\hline Гапоненко, А.Л. [17] & $\begin{array}{l}\text { Процесс систематического, сознательного, целенаправленного воздействия } \\
\text { людей на общественную систему в целом или ее отдельные звенья (производ- } \\
\text { ство, социальную и он духовную жизнь, отрасли экономики и др.) на основе } \\
\text { он познания и использования присущих обществе объективных закономерно- } \\
\text { стей и прогрессивных тенденций в интересах обеспечения его эффективного } \\
\text { он функционирования и развития }\end{array}$ \\
\hline Асаул, А.Н. [18] & $\begin{array}{l}\text { Деятельность по организации систем с целью обеспечения их целостности, } \\
\text { поддержания оптимального функционирования для решения поставленных } \\
\text { задач }\end{array}$ \\
\hline Бгашев М.В. [19] & $\begin{array}{l}\text { Разновидность трудовой деятельности. Определенный тип взаимодействия, } \\
\text { существующий между двумя субъектами, один из которых субъект управле- } \\
\text { ния, а другой объект }\end{array}$ \\
\hline $\begin{array}{l}\text { Термины основ } \\
\text { менеджмента [20] }\end{array}$ & $\begin{array}{l}\text { Это определенный тип взаимодействия двух объектов, один из которых при } \\
\text { этом находится в позиции субъекта управления, а другой - в позиции объекта } \\
\text { управления. }\end{array}$ \\
\hline $\begin{array}{l}\text { Воронков А.Н., } \\
\text { Колосова Т.В. [21] }\end{array}$ & $\begin{array}{l}\text { 1) Воздействие на результаты работы системы для достижения намеченной } \\
\text { цели; } \\
\text { 2) Процесс разного рода воздействия на систему изменяющих (или сохраняю- } \\
\text { щих) выходные значения показателей функционирования в системе, в задан- } \\
\text { ном направлении (на заданную величину); } \\
\text { 3) Функция системы, ориентированная или на сохранение ее основного каче- } \\
\text { ства, или на выполнение некоторой программы, обеспечивающей достижение } \\
\text { определенных целей. }\end{array}$ \\
\hline
\end{tabular}


цепций менеджмента и определение целевых установок развития российских моделей управления». Целю данной статьи является выявление на основе анализа базы научной электронной библиотеки Elibrari.ru наиболее цитируемых статей отечественных авторов, посвященных вопросам управления, планирования и организации деятельности современного предприятия. В ходе проведения исследования был произведен анализ литературных источников, и предпринята попытка систематизации существующих направлений развития теории управления организацией, а также формирование нового взгляда на область исследования вопросов в анализируемой области за последние 6 лет.

Проведение литературного обзора позволит создать некоторую базу отечественных исследований и выявить зависимости между основными направлениями исследований управленческой деятельности, обеспечив при этом транспарентность критической оценки их исследований. Понимание, полученное в ходе проведения таких литературных обзоров позволит расширить области исследований в данном направлении и обеспечит целенаправленную, прозрачную и надежную оценку исследовательских предпочтений за счет сокращения уровня предвзятости.

Исследование проводилось в последовательности, представленной на рисунке 1 .

Остановимся подробнее на каждом из этапов.
Эman 1. Определение вопросов исследования - подразумевает постановку цели и задач исследования. На этапе выявления основной тематики исследования авторами был определен круг решаемых задач: выявление особенностей процессов управления в современных условиях, определение новых областей исследования и перспектив развития в современных условиях. На основании чего была поставлена следующая цель исследования - на основе анализа научных трудов выявить основные направления и перспективы развития науки управления в современных условиях.

Эman 2. Отбор научных статей соответствующей тематики из базы Elibrari.ru. В рамках данного этапа авторами был определен круг научных баз и библиотек, в рамках которых была определена выборка статей для научного исследования. Период поиска был ограничен шестью годами публикаций (с 2016 по 2021 год исследований), также были определены минимальные значения цитируемости научных статей (статьи цитируемостью ниже 30 не рассматривались). Учитывая особенности научной электронной библиотеки Elibrari.ru, поисковые запросы были настроены на поиск словосочетаний «Организация, планирование и управление» в научных статьях, включенных в базу РИНЦ с сортировкой по максимальному объему цитирований. В результате заданных параметров поисковой систе-

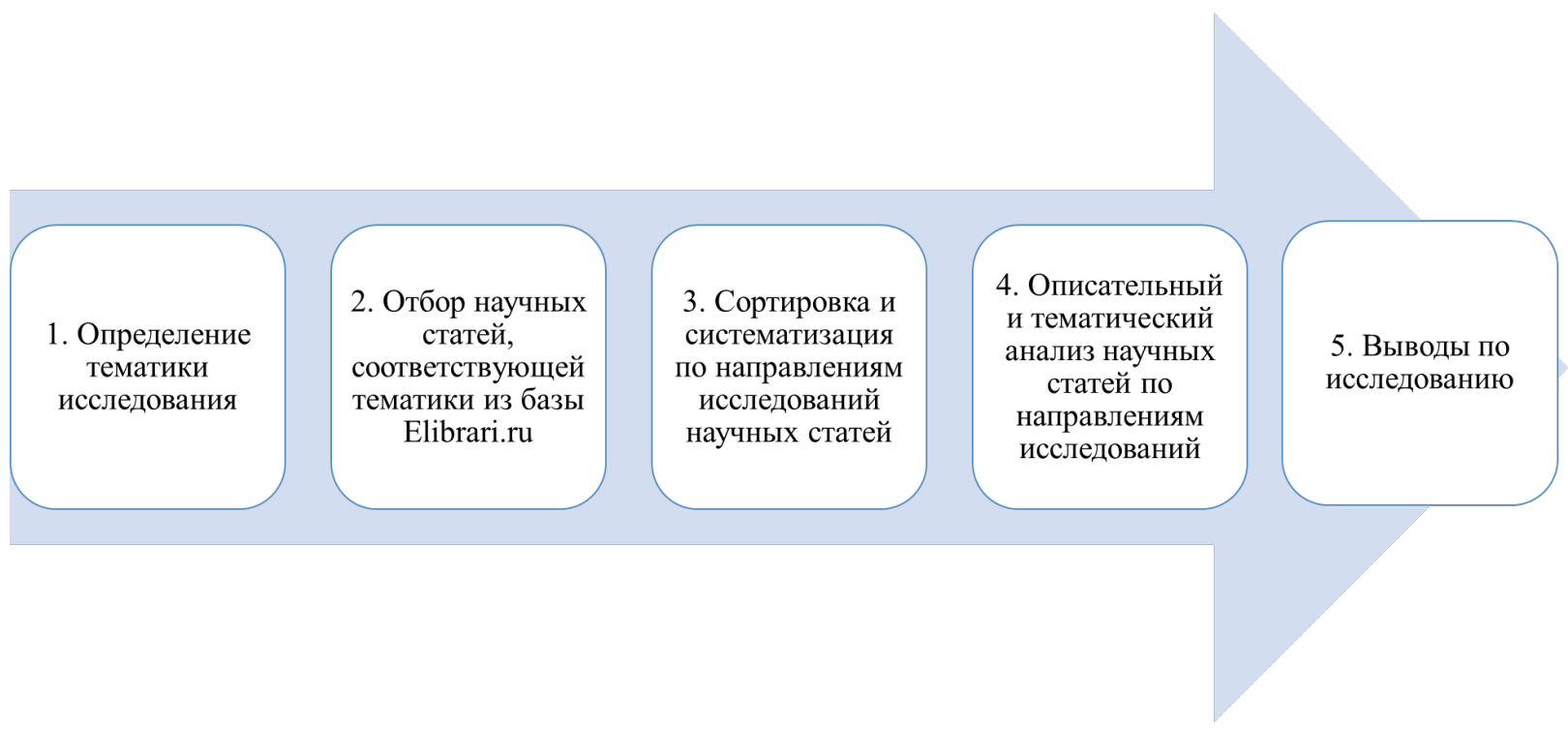

Рuc. 1. Основные этапы проведения исследования 
мой научной электронной библиотеки Elibrari. ru было выделено 8428 статей: 1481 публикаций было выпущено в 2016 году, 1664 в 2017 году, 1478 в 2018 году, 1508 в 2019 году, 1391-2020 году и 906 в 2021 году. Тем не менее данный протокол исследований выявил широкий спектр вопросов, не в полной мере связанный с поисковыми запросами и не отвечающих тематике исследования, поэтому из выборки были исключены статьи, выходящие за рамки данного исследования и не относящиеся к экономической тематике исследования. В соответствии с условиями ограничений и по цитируемости (не ниже 30) ситуация выглядит следующим образом: 32 статьи в 2016 году, 38-2017 год, 19-2018 год, 5-2019 год, 2-2020 год и 0-2021 год. Всего из общей выборки требованиям соответствовало 96 статей. Соотношение всей базы публикаций исследуемой тематики и статей, отвечающих требованиям анализа представлено на рисунке 2.

Эman 3. Сортировка и систематизация по направлениям исследований научных статей. На данном этапе были выделены основные направления, которым отвечают исследования последних лет. Среди основных направлений исследований отечественных ученых в области управления организацией можно выделить:

цифровизация - 25 статей;

управление - 16 статей; планирование - 16 статей;

образование - 7 статей; промышленность и АПК (сельское хозяйство) - 6 статей;

экономическая политика -5 статей;

публичное управление - 3 статьи;

импортозамещение - 2 статьи;

технологический уклад (революция) -2 статьи;

устойчивое развитие -2 статьи;

модернизация -1 статья;

организация - 1 статья;

пандемия - 1 статья;

социально-экономическая система -1 статья;

экономическая безопасность - 1 статья;

экономическая теория -1 статья.

На основании полученных данных было построено дерево научных исследований в области международного бизнеса, представленное на рисунке 3.

При рассмотрении направленности публикаций авторами было обнаружено отсутствие публикаций, связанных с описанием концептуальных и методологических основ развития и становления управления и планирования, как с точки зрения исторического развития, так и со стороны современных подходов. Все это говорит об отсутствии возможности отражения в последующих исследованиях авторов достоинств, недостатков и дальнейших перспектив развития

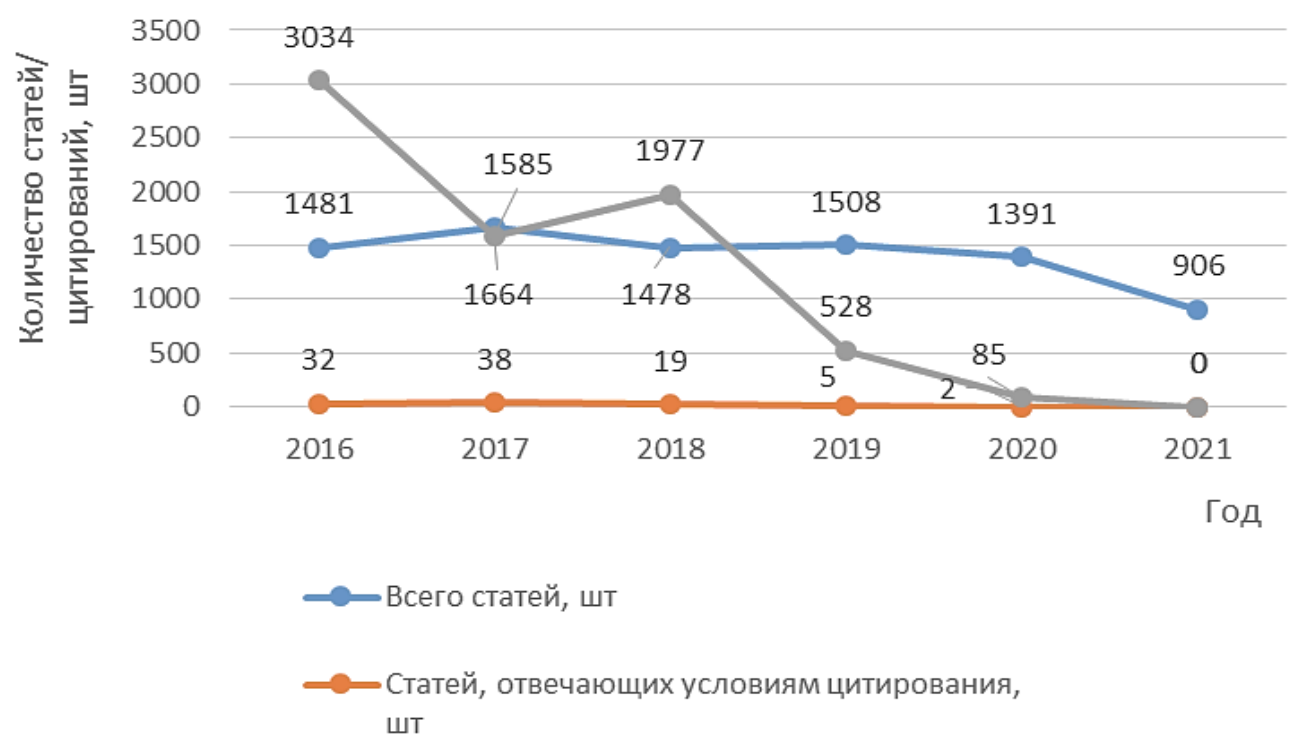

Puc. 2. Количество публикаций по поисковому запросу «Организация, планирование и управление» за период с 2016 по 2021 г. 


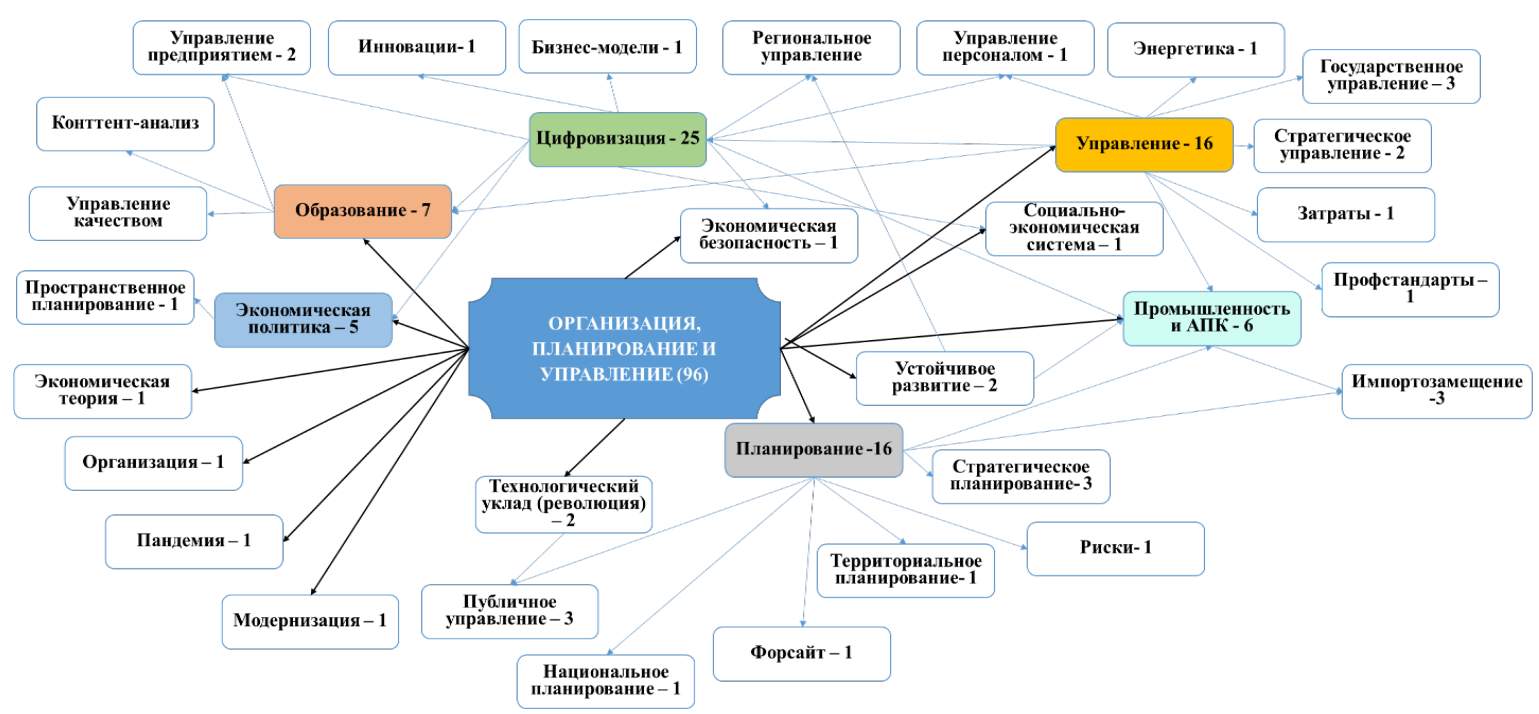

Puc. 3. Направления исследований и количество научных работ в выборке по поисковому запросу «организация, планирование и управление»

концепций в исследуемой области.

Эman 4. Описательный и тематический анализ научных статей по направлениям исследований. Данный этап подразумевал детальный анализ научных статей в соответствии с периодом и местом издания.

Обзор научных литературных источников показал, что, несмотря на высокие темпы роста интереса ученых к вопросам планирования и управления, имеется некоторая узость в рассмотрении вопросов исследования. Темы управления процессами модернизации, организации управления, влияния пандемии на процессы управления и планирования, особенности экономической безопасности и экономической теории в области управления и планирования освещаются в единичном порядке, в отдельных экономических журналах, поэтому в процессе детального анализа были исключены единичные публикации по исследуемой тематике и выделены шесть основных направлений исследований (рисунок 4).

Данный анализ показал, что вопросы организации, планирования и управления интересны на протяжении всего периода исследований. Выявлено, что при рассмотрении данной темы российскими учеными, особая роль отводится таким областям как:

- цифровизация, в рамках которой широкое распространение получили вопросы управления предприятием и образовательная деятельность,

- экономическая политика с углубленным исследованием в области пространственного планирования;

- образовательная деятельность в разрезе управления качеством представляемых услуг, подготовки кадров для современной экономики и цифровизации процесса образования;

- развитие отраслей промышленности и сельского хозяйства в современных условиях импортозамещения;

- планирование с углублением в сторону публичного управления, форсайт-технологий и стратегического планирования;

- управление в области государственного управления стратегического развития и др.

Следует отметить, что по выявленным основным направлениям в 2016 году было опубликовано 17 статей, в 2017-32 статьи, в 201817 статей, в 2019-5 статей, в 2020 и 2021 годах статей, соответствующим условиям отбора, по данным направлениям не опубликовано. Среди изданий ведущую роль заняли: International Journal of Open Information Technologies, Вестник Мининского университета, Вопросы экономики, Государственное и муниципальное управление. Ученые записки СКАГС, Инновационная экономика: перспективы развития и совершенствования, Интернет-журнал Науковедение, Национальные интересы: приоритеты и безопасность и др.

Совмещая картину основных направлений и годов издания можно получить следующую картину (рисунок 5):

Указанные основные направления исследовательской деятельности в области планирова- 


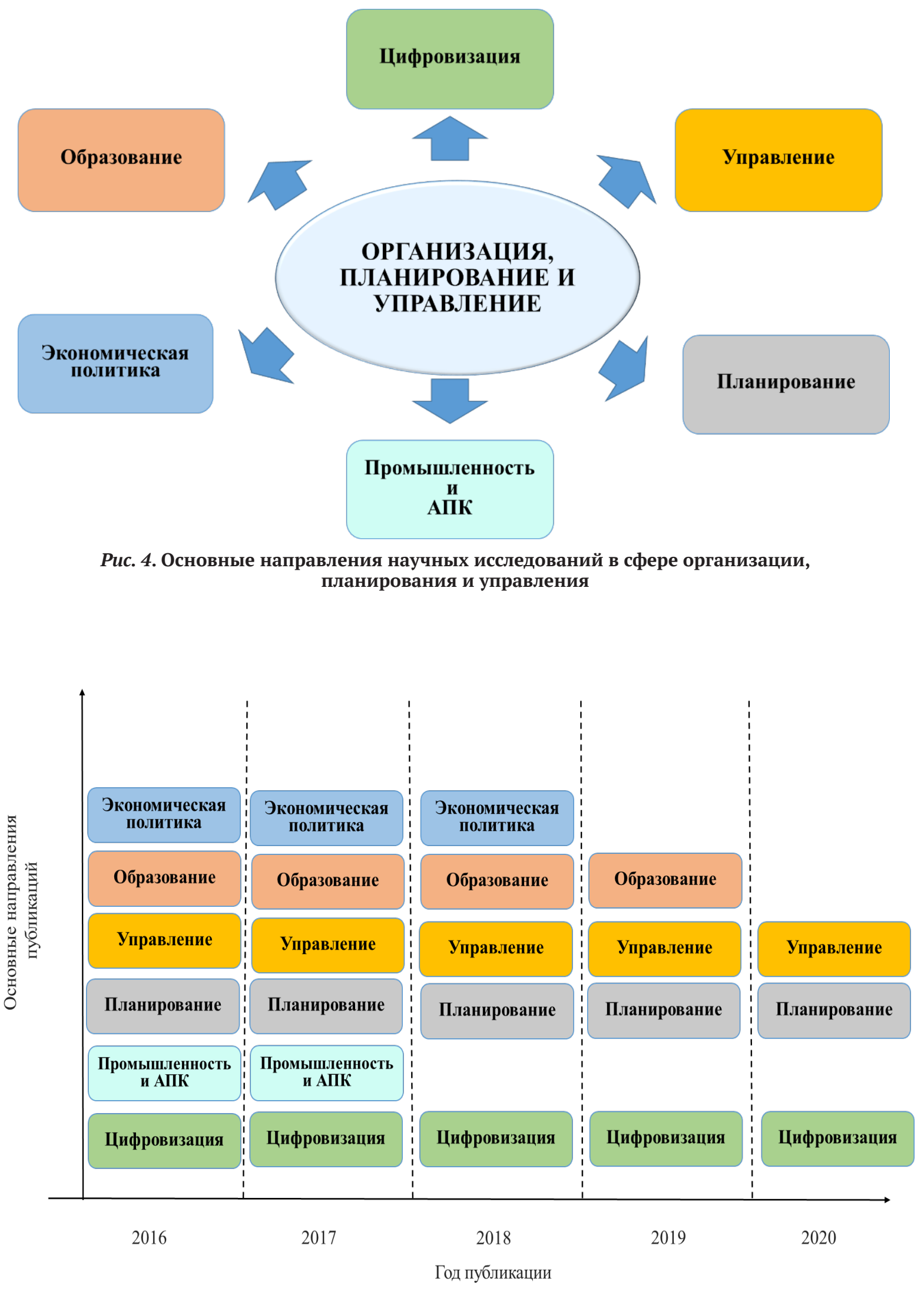

Puc. 5. Публикации статей с разбивкой по основным направлениям 
ния и управления позволили выявить три основные проблемные области, которым посвящено наибольшее количество статей (цифровизация, планирование и управление).

Эman 5. Выводы по исследованию. На данном этапе проводится оценка результатов анализа, взаимосвязь публикаций и направлений исследования, их интеграция, синергия и прочее.

Проведенное исследование подтвердило предварительную гипотезу о малой изученности вопросов концептуальных и методологических основ развития управленческой науки и их незначительное отражение в трудах отечественных авторов за анализируемый период. Такие исследования позволили бы расширить круг рассматриваемых вопросов и возможность мультинаправленных исследований предметной области. В результате глубоких исследований отечественная наука может приобрести дополнительное преимущество в сфере трансформации концепций и технологий менеджмента и их методического обоснования. Это позволит создать связи с имеющимися исследованиями с обособленными исследованиями в каждой конкретной сфере. Кроме этого дополнительного изучения требует проблемное поле в области устойчивого развития и стратегического планирования. Более подробное исследование данных вопросов позволит провести анализ предметной области в долгосрочной перспективе и спрогно- зировать пути развития управленческой науки с учетом изменений, обусловленных четвертой промышленной революцией. Все это приведет к формированию и развитию концептуальных и методических основ по анализируемой проблеме.

Выводы. Исследования в области планирования и управления, учитывая масштабы публикационной активности и большое количество проблемных вопросов, имеют большое значение для развития как отдельно взятых организаций, так и экономических систем большего масштаба. Одновременно с этим данная область исследований имеет высокий уровень сложности изучения ввиду большого количества объектов и субъектов исследования, вовлеченных в процессы трансформации. В рамках данной статьи авторами предпринята попытка анализа публикаций, выявления динамики развития предметной области, а также новых направлений исследований, которые являются перспективными для развития отечественный науки. Проведенный анализ позволил эмпирически представить исследуемую проблему, а также отразить основные моменты ее восприятия российскими учеными. Исследование может быть полезно в понимании переходного состояния управленческой науки и способствует более детальному рассмотрению выявленных проблемных областей.

\section{Библиографический список}

1. Schwab K. (2017) The Fourth Industrial Revolution. Crown Business, New York.

2. Андреева Т.А. Развитие интегрированной системы менеджмента качества и стратегического управления предприятий промышленности / Дисс. док. эк. наук. Саратов. 2016

3. Ансофф И. Стратегический менеджмент / И. Ансофф. - СПб.: Изд-во: «Питер», 2009. - 344 с.

4. Антонов, В.Г., Кузьмина, Е. Ю. Факторы и тенденции развития менеджмента / В. Г. Антонов, Е. Ю. Кузьмина// Вестник Университета (Государственный университет управления). - 2015. - № 3 - C. 90-93

5. Weber M. (2016) Economy and Society: An Outline of Interpretive Sociology (2 Volume Set). University of California Press.

6. Денисов, И. В., Потапов, Р.А.Становление и развитие менеджера / И.В.Денисов, Р. А.Потапов // Научноаналитический журнал Наука и практика Российского экономического университета им. Г.В.Плеханова. - 2017. - № 2 (26). - С. 28-33.

7. улапов М.Н., Варфоломеев В.П., Карасев П.А. Технологические аспекты теории управления инновационными процессами: системный анализ и подходы к моделированию // Друкеровский вестник. 2018. № 3 (23). C. 82-100.

8. Новикова Ю.С. О некоторых проблемах управления крупными российскими организациями // Вопросы экономики и права. 2011. № 3.

9. Никулин Л. Ф., Деменко О. Г. «Четвертая парадигма» и менеджмент / Л. Ф. Никулин, О. Г. Деменко // Научноаналитический журнал наука и практика Российского экономического университета им. Г. В.Плеханова. 2018. - № 1 (29). - С. 48-63. 
10. Кулапов М. Н., Одегов Ю. Г., Никулин Л. Ф. О некоторых взглядах на «менеджмент 3.0» (новая редакция)/М.Н. Кулапов Ю.Г. Одегов Л.Ф.Никулин// Управленец. - 2011. - С. 26-31

11. Тейлор Ф. Принципы научного менеджмента. URL: https://readli.net/chitat-online/?b=914760\&pg=1 (дата обращения: 14.10 .2020$)$

12. Файоль А., Эмерсон Г., Тейлор Ф., Форд. Г. Управление это наука и искусство. М: Республика, 1992.349 с.

13. Бондаренко И.В. Эффективность управления предприятием - ключевая задача менеджмента / И. В.Бондаренко. - М.: ИПО «МП». 2013. - 643 с.

14. Абчук В.А. Менеджмент / В.А. Абчук. - СПб.: Издательство «Союз», 2012. - 463 с.

15. Виноградова С. Н. Коммерческая деятельность / С. Н. Виноградова, О. В. Пигунова. - Мн.: Высшая школа, 212. -352 c

16. Иванова Е. А. Корпоративное управление / Е. А. Иванова, Л. В.Шишикина. - М.: Наука, 2017. - 255 с

17. Гапоненко А. Л. Стратегическое управление / А. Л.Гапоненко. - М.: Омега, 2011. - 472 с

18. Асаул А. Н. Менеджмент корпорации и корпоративное управление / А.Н. Асаул, В.И.Павлов, Ф.И.Бескиерь, О.А. Мышко. - СПб.: Гуманистика, 2016. - 328 с.

19. Бгашев M.В. Управленческий словарь. Современная управленческая наука в понятиях и терминах URL: http://elibrary.sgu.ru/uch_lit/1861.pdf (Дата обращения 15.10.2021 г)

20. Стратегия и Управление.ru URL: https://strategplann.ru/introduction-to-management/terms-principles-ofmanagement.html (Дата обращения 16.11.2021

21. Воронков А.Н., Колосова Т.В. Словарь по менеджменту URL: https://bibl.nngasu.ru/electronicresources/uchmetod/management/851248.pdf (Дата обращения 23.12.2021) 